\title{
Physiologic evaluation of coronary lesions using instantaneous wave-free ratio (iFR) in patients with severe aortic stenosis undergoing transcatheter aortic valve implantation
}

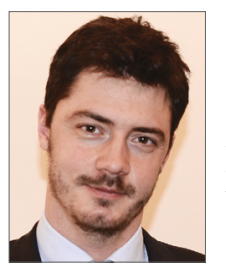

Roberto Scarsini ${ }^{1}$, MD; Gabriele Pesarini ${ }^{1}$, MD; Carlo Zivelonghi , MD; Anna Piccoli ${ }^{1}, \mathrm{MD}$; Valeria Ferrero ${ }^{1}$, MD; Mattia Lunardi ${ }^{1}$, MD; Leonardo Gottin ${ }^{2}$, MD; Claudia Zanetti ${ }^{1}$, MD; $^{2}$ Giuseppe Faggian³, MD; Flavio Ribichini ${ }^{*}$, MD

1. Division of Cardiology, Department of Medicine, University of Verona, Verona, Italy; 2. Division of Anaesthesiology, Department of Surgery, University of Verona, Verona, Italy; 3. Division of Cardiac Surgery, Department of Surgery, University of Verona, Verona, Italy

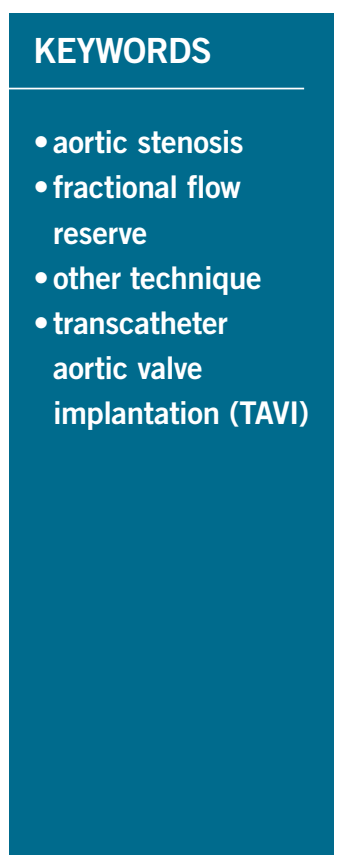

\begin{abstract}
Aims: We sought to assess eventual changes in iFR measurements in patients with aortic stenosis (AS) before and after TAVI in coronary lesions with different degrees of angiographic severity.

Methods and results: The functional relevance of 145 coronary lesions was assessed by online iFR and FFR measurement in 66 patients with severe AS before and after TAVI, during the same procedure. The iFR-FFR classification agreement was calculated for pre-TAVI and post-TAVI measurements. Mean iFR values remained identical before and after TAVI, irrespective of the angiographic severity of the coronary stenosis $(0.89 \pm 0.12$ vs. $0.89 \pm 0.12, \mathrm{p}=0.66)$. However, individual iFR values varied widely after TAVI and the $0.89 \mathrm{iFR}$ threshold was crossed by $15 \%$ of the investigated coronary lesions. Higher iFR variation was related to a higher transaortic gradient drop after valve intervention. The diagnostic accuracy of iFR in predicting an FFR $\leq 0.8$ was poor (65\%) in lesions with severe obstructions, and tended to increase post TAVI.

Conclusions: Although overall values did not change after TAVI, iFR presented significant and mostly erratic individual variations after valve replacement. Delta iFR was influenced by the extent of the transaortic gradient drop induced by TAVI. Therefore, caution is advisable in the interpretation of iFR in the presence of AS.
\end{abstract}

\footnotetext{
*Corresponding author: Division of Cardiology, Department of Medicine, University of Verona, Piazzale Aristide Stefani 1, 37126 Verona, Italy.E-mail: flavio.ribichini@univrit
} 


\section{Abbreviations}

AS

aortic stenosis

AUC

area under the curve

CAD

CFR

coronary artery disease

coronary flow reserve

DS

diameter stenosis

FFR fractional flow reserve

iFR instantaneous wave-free ratio

QCA quantitative coronary analysis

TAVI transcatheter aortic valve implantation

TTE transthoracic echocardiography

\section{Introduction}

The optimal strategy to assess the functional severity of concomitant coronary artery disease (CAD) in aortic stenosis (AS) is difficult to define ${ }^{1}$. Moreover, coronary flow reserve (CFR) is attenuated in patients with AS, even in the absence of coronary obstructions $^{2}$.

Fractional flow reserve (FFR) might have some limitations in severe AS, mainly because of the impaired maximal hyperaemia achievable due to the microvascular dysfunction frequently observed in $\mathrm{AS}^{2-5}$. Recently, we demonstrated that, although overall FFR values do not change before and immediately after TAVI, positive and borderline FFR values significantly decrease after TAVI $^{6}$.

The instantaneous wave-free ratio (iFR) is a hyperaemia-free index calculated at rest without the need for pharmacologic vasodilation $^{7}$. iFR has been proposed as an alternative means for assessing CAD in AS without the need for high doses of vasodilators $^{1}$ and, as such, it may be preferred in patients with severe AS. However, iFR has never been validated before in AS patients.

In the present analysis, we formulated the hypothesis that iFR is influenced by the presence of severe AS. The changes in pressure load and coronary flow that are going to occur immediately after TAVI are likely to alter the resting conditions investigated by iFR. Indeed, it has been demonstrated that CFR, closely linked to $\mathrm{iFR}^{8}$, increases significantly after TAVI ${ }^{9}$. Therefore, the results of physiological assessment by means of iFR may vary significantly after aortic valve replacement, especially in coronary lesions with borderline results at the pressure wire interrogation.

\section{Editorial, see page 1499}

\section{Methods}

The study protocol has been described previously ${ }^{6}$. Briefly, in this prospective, observational study, iFR and FFR measurements were attempted in the three major epicardial coronary arteries of patients with AS and associated CAD before and immediately after TAVI, maintaining similar haemodynamic conditions. We assessed the eventual changes in iFR measurements before and after aortic valve replacement in different subgroups of coronary lesions. In particular, we investigated those coronary lesions in which the iFR value crossed the 0.89 cut-off value after TAVI, changing the indication to myocardial revascularisation.
The study was approved by the ethical review board of the University of Verona (ID CESC 2015-498), and all patients eligible for the protocol provided written consent.

Fifty-four out of the 66 patients reported here belong to a series previously reported ${ }^{6}$.

\section{PATIENT SELECTION}

Patients included in the study had severe, symptomatic AS defined according to current ESC Guidelines ${ }^{10}$, at least one coronary artery stenosis, and a clinical indication to elective TAVI as jointly evaluated by the Heart Team. Inclusion and exclusion criteria were the same as reported previously ${ }^{6}$.

Severe AS was confirmed by transthoracic echocardiography (TTE) as recommended. Aortic gradients, valvular areas and left ventricular function were measured before and after valve replacement using TTE. All TAVI procedures, including haemodynamic, iFR and FFR measurements, were performed by the percutaneous transfemoral approach under local anaesthesia and only mild conscious sedation. None of the patients included in the analysis required intravenous pressure support.

The choice of the aortic valve prosthesis was left to the operator's discretion. The Medtronic CoreValve ${ }^{\circledR}$ Evolut $^{\mathrm{TM}} \mathrm{R}$ bioprosthesis (Medtronic, Minneapolis, MN, USA) or Edwards SAPIEN 3 bioprosthesis (Edwards Lifesciences, Irvine, CA, USA) was used in this study.

\section{CORONARY ANGIOGRAPHY AND QUANTITATIVE CORONARY ANALYSIS}

Coronary angiography was performed by a standard percutaneous femoral approach with 6 Fr guiding catheters using the same vascular access predetermined for the valve implantation ${ }^{11}$. The severity of the CAD was graded by QCA performed off-line by expert operators blinded to the FFR and iFR results using the software package CAAS-II QCA (Pie Medical Imaging, Maastricht, the Netherlands) in a previously validated core laboratory (NBR, Verona, Italy) ${ }^{12}$.

Arteries showing minimal angiographic lesions with a percent diameter stenosis ( $\% \mathrm{DS}) \leq 30 \%$ were considered angiographically unobstructed; those with a $\% \mathrm{DS} \geq 30 \leq 50$ were classified as having intermediate lesions, and those with $\% \mathrm{DS}>50 \%$ as having significant lesions.

\section{INTRACORONARY PRESSURE MEASUREMENTS}

A pressure monitoring guidewire (PrimeWire ${ }^{\circledR}$; Volcano Corporation, Rancho Cordova, CA, USA) was advanced distally to the coronary artery stenosis after normalisation. Hyperaemia was obtained after administration of an intracoronary bolus of a high dose (150 to $250 \mathrm{mg}$ ) of adenosine as previously indicated by other authors, who reported equivalent diagnostic capabilities compared to i.v. infusion ${ }^{9,13,14}$. Nitroglycerine was not administered, given the presence of severe $\mathrm{AS}^{6,9}$. An FFR value $\leq 0.80$ was considered pathologic according to current recommendations ${ }^{14}$. iFR was measured online before FFR, and using the Volcano iFR computational algorithm. An iFR cut-off value of 0.89 was considered 
equivalent to the $0.80 \mathrm{FFR}$ value for the determination of ischaemia-provoking stenosis ${ }^{15}$.

\section{STATISTICAL ANALYSIS}

Continuous variables are presented as mean and standard deviation (SD) whereas categorical variables are presented as frequencies (percentages).

Comparison of variables before and after TAVI was performed using a repeated measures mixed model, with vessel nested within patient. The TAVI effect was considered as a binary variable (before vs. after TAVI). Linear regression analysis was used to test the association of delta iFR between pre and post TAVI with other variables.

Sensitivity, specificity and area under the curve (AUC) were defined from the calculated receiver operating characteristic (ROC) curve. The diagnostic accuracy of iFR was defined as the proportion of correctly classified lesions (against FFR) among all coronary obstructions.

A p-value $<0.05$ was considered statistically significant. All statistical analyses were performed using Stata/SE 14.0 (StataCorp LP, College Station, TX, USA).

\section{Results \\ PATIENT POPULATION}

Between January 2015 and February 2017, 66 patients with severe and symptomatic AS with concomitant CAD underwent TAVI and concluded all the study protocol steps, that included the online iFR and FFR measurements before and after TAVI on 145 coronary lesions.

Twenty-one patients received a CoreValve Evolut $\mathrm{R}$ valve, and 45 patients received an Edwards SAPIEN 3 valve. Baseline and angiographic characteristics of the overall patient cohort are shown in Table 1.

Patients had predominantly angiographically intermediate stenosis, with $80 \%$ of lesions showing between 30 and $70 \% \mathrm{DS}$ following a normal distribution. Mean percentage diameter stenosis was $45 \pm 13.8 \%$ (Figure 1). Mean pre-TAVI FFR and iFR were $0.88 \pm 0.09$ and $0.89 \pm 0.12$, respectively. The proportion of stenosis with post-TAVI FFR values lower than $0.80,0.75,0.60$, and 0.50 was $22.6 \%, 14.6 \%, 5.8 \%$, and $1.4 \%$, respectively.

\section{EFFECT OF TAVI ON FUNCTIONAL ASSESSMENT OF CORONARY LESIONS}

During the whole procedure all patients remained awake, and their haemodynamic parameters did not change before and after TAVI (Table 2).

TAVI effect had no significant interaction with the overall iFR measurements $(\mathrm{z}=0.44, \mathrm{p}=0.66)$. In fact, overall $\mathrm{iFR}$ values did not change after TAVI compared with baseline $(0.89 \pm 0.12$ vs. $0.89 \pm 0.11$ ). Even including the baseline iFR group in the model as a binary variable (positive if the ratio was less or equal to 0.89 and negative if greater than 0.89), its interaction with TAVI effect was not statistically significant $(\mathrm{z}=0.05, \mathrm{p}=0.82)$, indicating no significantly different trend in the average iFR values between the two groups.
Table 1. Clinical and angiographic characteristics of the studied cohort.

\begin{tabular}{|l|c|c|c|c|}
\hline \multicolumn{1}{|c|}{ Variable } & $\begin{array}{c}\text { Overall } \\
\text { population }\end{array}$ & $\begin{array}{c}\text { iFR pre } \\
\text { post-TAVI } \\
\text { concordance }\end{array}$ & $\begin{array}{c}\text { iFR pre } \\
\text { post-TAVI } \\
\text { discordance }\end{array}$ & p-value \\
\hline Demographic data \\
\hline Number of patients & 66 & 48 & 18 & - \\
\hline Age, years & $80 \pm 7$ & $83 \pm 6$ & $79 \pm 5$ & 0.02 \\
\hline Sex, male, \% & 45.1 & $17(41 \%)$ & $7(41 \%)$ & 0.96 \\
\hline Dyslipidaemia, \% & 81 & $18(43 \%)$ & $9(53 \%)$ & 0.57 \\
\hline Hypertension, \% & 79.3 & $41(98 \%)$ & $16(94 \%)$ & 0.5 \\
\hline Smoking, \% & 47.3 & $20(47 \%)$ & $8(47 \%)$ & 0.9 \\
\hline Diabetes mellitus, \% & 49.7 & $9(21 \%)$ & $4(24 \%)$ & 0.99 \\
\hline Ejection fraction, \% & $52 \pm 10$ & $53 \pm 14$ & $50 \pm 12$ & 0.48 \\
\hline S-creatinine, mg/dL & $1.2 \pm 1$ & $1.3 \pm 1$ & $1 \pm 0.2$ & 0.31 \\
\hline $\begin{array}{l}\text { AV mean gradient pre } \\
\text { TAVI, mmHg }\end{array}$ & $45 \pm 16$ & $45 \pm 12$ & $44 \pm 22$ & 0.85 \\
\hline $\begin{array}{l}\text { AV mean gradient post } \\
\text { TAVI, mmHg }\end{array}$ & $10 \pm 4$ & $10 \pm 4$ & $12 \pm 5$ & 0.31 \\
\hline Angiographic characteristics & 145 & 124 & 21 & - \\
\hline Number of lesions & $11.8 \pm 6$ & $12 \pm 6$ & $11 \pm 8$ & 0.35 \\
\hline Lesion length, mm & $2.9 \pm 0.8$ & $2.9 \pm 0.6$ & $2.9 \pm 0.5$ & 0.89 \\
\hline D-ref, mm & $1.8 \pm 0.5$ & $1.8 \pm 0.7$ & $1.7 \pm 0.6$ & 0.72 \\
\hline MLD, mm & $45 \pm 13.8$ & $41.4 \pm 19.5$ & $41 \pm 19.4$ & 0.93 \\
\hline$\%$ \% & $0.89 \pm 0.12$ & $0.89 \pm 0.12$ & $0.89 \pm 0.02$ & 0.84 \\
\hline Mean iFR ratio & $0.88 \pm 0.09$ & $0.88 \pm 0.12$ & $0.88 \pm 0.06$ & 0.99 \\
\hline Mean FFR ratio & & & \\
\hline $\begin{array}{l}\% \text { \%S: percent diameter stenosis; D-ref: reference diameter; FFR: fractional flow reserve; } \\
\text { MLD: minimal lumen diameter }\end{array}$ & & & \\
\hline
\end{tabular}

Positive iFR values $(\leq 0.89)$ at baseline were found in 58 out of $145(40 \%)$ lesions. The average iFR measurements in this subgroup were comparable after TAVI $(0.77 \pm 0.13$ vs. $0.79 \pm 0.11)$.

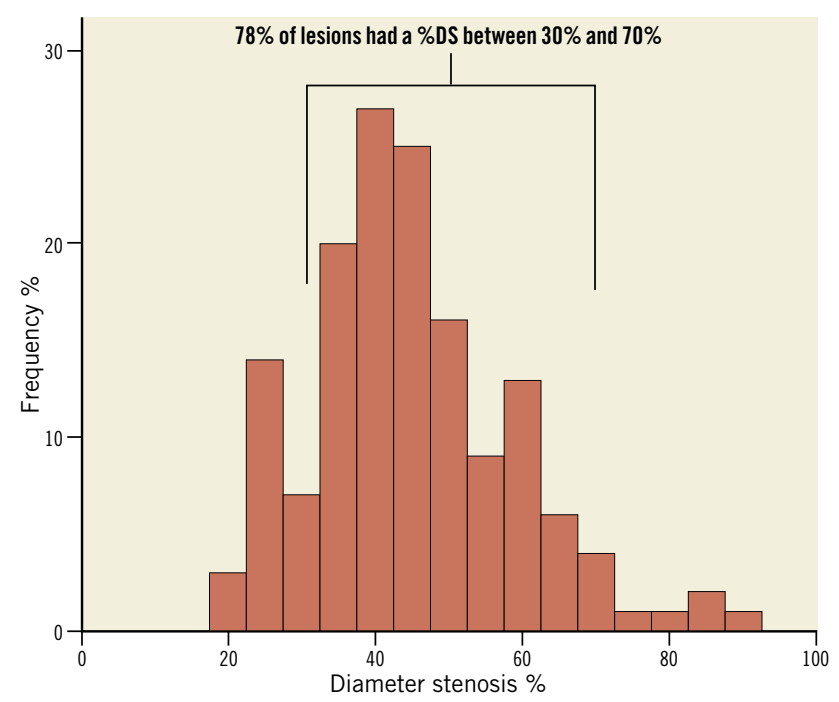

Figure 1. The majority of lesions were classified as angiographic intermediate, with mean $\% D S 45 \% \pm 13.8$ and $78 \%$ of $\% D S$ values between $30 \%$ and $70 \%$. 
Table 2. Preprocedural and post-procedural haemodynamic and echocardiographic characteristics.

\begin{tabular}{|l|c|c|c|}
\hline \multicolumn{1}{|c|}{ Variables } & Pre TAVI & Post TAVI & p-value \\
\hline SBP, mmHg & $127 \pm 14.3$ & $134 \pm 15$ & 0.14 \\
\hline DBP, $\mathrm{mmHg}$ & $75.6 \pm 9.4$ & $73.4 \pm 10$ & 0.21 \\
\hline $\mathrm{HR}, \mathrm{bpm}$ & $80.3 \pm 12$ & $76 \pm 9.7$ & 0.04 \\
\hline CVP, $\mathrm{mmHg}$ & $10 \pm 4$ & $12 \pm 3.8$ & 0.1 \\
\hline AVA, $\mathrm{cm}^{2}$ & $0.68 \pm 0.09$ & $1.9 \pm 0.7$ & $<0.001$ \\
\hline AVPG mean, $\mathrm{mmHg}$ & $45.5 \pm 15.4$ & $10.2 \pm 3.7$ & $<0.001$ \\
\hline AVPG max, mmHg & $71.7 \pm 20.8$ & $18.1 \pm 7.7$ & $<0.001$ \\
\hline AVA: & &
\end{tabular}

AVA: aortic valve area; AVPG: aortic valve pressure gradient; bpm: beats per minute; CVP: central venous pressure; DBP: diastolic blood pressure; HR: heart rate; SBP: systolic blood pressure

Similarly, no significant variations were found before and after TAVI in the subgroup of coronary lesions with negative iFR value $(0.96 \pm 0.03$ vs. $0.95 \pm 0.05)$.

No significant differences were found comparing the clinical and angiographic characteristics of the two subgroups. A trend towards higher serum creatinine was observed among patients with negative baseline iFR ( $1.42 \pm 1$ vs. $1.1 \pm 0.33, \mathrm{p}=0.06)$.

When the coronary vessel was added to the model (LAD versus non-LAD), no significant interaction with TAVI effect was evident $\left(\chi^{2}=4.64, p=0.1\right)$, indicating a similar trend between the two groups. Mean iFR values in LAD varied from $0.84 \pm 0.11$ at baseline to $0.85 \pm 0.11$ after TAVI. In non-LAD coronary arteries, the iFR measurements were $0.93 \pm 0.1$ before TAVI and $0.93 \pm 0.13$ after TAVI.

\section{EFFECT OF TAVI ON CORONARY LESIONS STRATIFIED BY QCA}

When \%DS was included in the model as a categorical variable, its interaction with TAVI had no statistical significance $\left(\chi^{2}=1.84\right.$, $\mathrm{p}=0.39$ ), indicating a similar trend between coronary lesions with $\% \mathrm{DS} \geq 50$ and those with $\% \mathrm{DS}<50$. In fact, the average iFR measurements were comparable before and after TAVI both in coronary obstructions with $\% \mathrm{DS} \geq 50(0.79 \pm 0.11$ vs. $0.78 \pm 0.11)$ and in those with $\% \mathrm{DS}<50(0.94 \pm 0.15$ vs. $0.93 \pm 0.1)$.

\section{IFR DIAGNOSTIC PERFORMANCE AND iFR-FFR CLASSIFICATION AGREEMENT}

The iFR diagnostic performance in predicting a positive FFR was high before and after TAVI ( $\mathrm{AUC}_{\text {preTAVI }}=0.90, \mathrm{CI}: 0.84-0.96$ vs. $\mathrm{AUC}_{\text {postTAVI }}=0.93, \mathrm{CI}: 0.88-0.97, \mathrm{p}=0.71$ ) (Figure 2). Using the 0.89 cut-off, the diagnostic accuracy of iFR was $76.5 \%$ before TAVI and $82.3 \%$ at post-TAVI assessment $(\mathrm{p}=0.27$ ) (Figure 3).

In coronary lesions with $\% \mathrm{DS}<50$, the iFR-FFR agreement was elevated and similar before and after TAVI ( 83.15 vs. $84.8 \%$, $\mathrm{p}=0.91$ ), whereas in those lesions with significant angiographic obstructions ( $\% \mathrm{DS} \geq 50$ ), the iFR-FFR agreement was poorer and tended to increase after TAVI (65.3 vs. $78.7 \%, \mathrm{p}=0.08)$.

Similarly, the iFR-FFR agreement was found to be poor in coronary lesions with baseline positive iFR values, both before TAVI and after TAVI ( $43.1 \%$ vs. $57.9 \%, \mathrm{p}=0.15)$. On the other hand, in those lesions with baseline negative functional evaluation (iFR

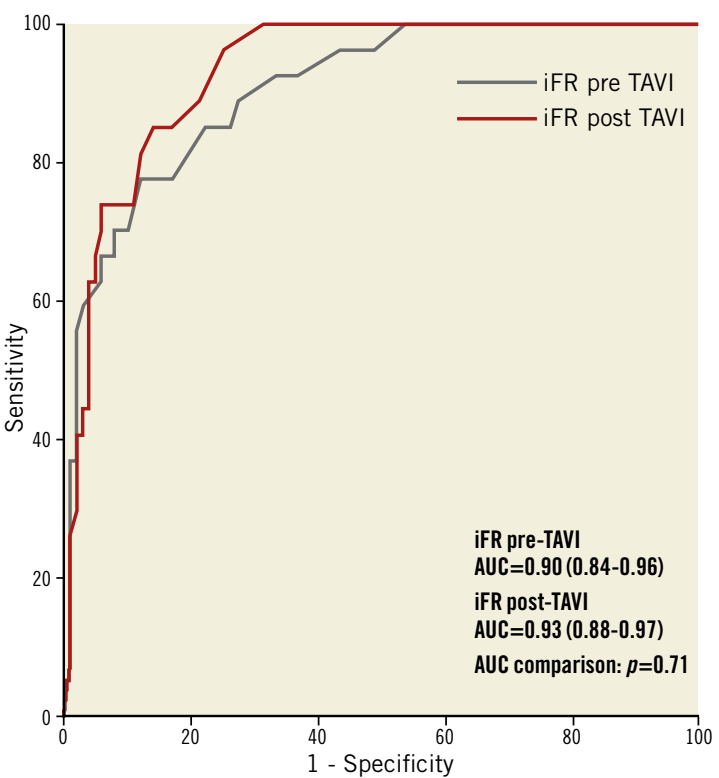

Figure 2. ROC curve comparison of iFR measurements before and after TAVI in predicting a post-TAVI positive FFR $(\leq 0.8)$.

$>0.89)$, the iFR-FFR agreement was significantly higher $(\mathrm{p}<0.0001)$ compared with functionally significant obstructions (iFR $\leq 0.89$ ) whether before TAVI or after TAVI (98\% vs. 90.1\%, $\mathrm{p}=0.06$ ).

\section{INDIVIDUAL iFR CHANGES BEFORE AND AFTER TAVI}

Although the mean iFR value did not change, a wide variation in the individual iFR measurements was observed before and after TAVI (Figure 4A).

Twenty-one out of 145 (14.5\%) overall coronary lesions in 18 out of $66(27.3 \%)$ patients crossed the 0.89 threshold after TAVI (Figure 4B). Negative baseline iFR values $(>0.89)$ shifted below the 0.89 threshold in 10 out of $87(11.5 \%)$ coronary lesions after TAVI. Baseline positive iFR values $(\leq 0.89)$ shifted above the 0.89 threshold in 11 out of $58(18.9 \%)$ coronary lesions. Of note, all these cases showed intermediate lesions at QCA (\%DS range, $37-70)$ and similar lesion length $(10.9 \pm 7.2 \mathrm{~mm})$ compared with that of coronary obstructions that did not cross the iFR cut-off $(12.3 \pm 5.7 \mathrm{~mm}, \mathrm{p}=0.53)$.

Of note, the FFR crossed the 0.8 threshold in only four out of 21 cases in this subgroup of lesions. Overall, FFR values crossed the 0.80 cut-off in $12(8.3 \%)$ lesions and $10(15 \%)$ patients.

No significant differences were observed between the clinical characteristics of patients with coronary lesions that crossed the 0.89 iFR threshold after TAVI compared with the rest of the study cohort. The only exception was the younger age of the group of patients who presented discordance in the iFR measurements pre and post TAVI ( $79 \pm 5$ vs. $83 \pm 6, \mathrm{p}=0.02$ ) (Table 1).

\section{DETERMINANTS OF INDIVIDUAL IFR VARIATION AFTER TAVI}

The average delta in iFR measurements before and after TAVI was $-0.004 \pm 0.063$ (Figure 5). 


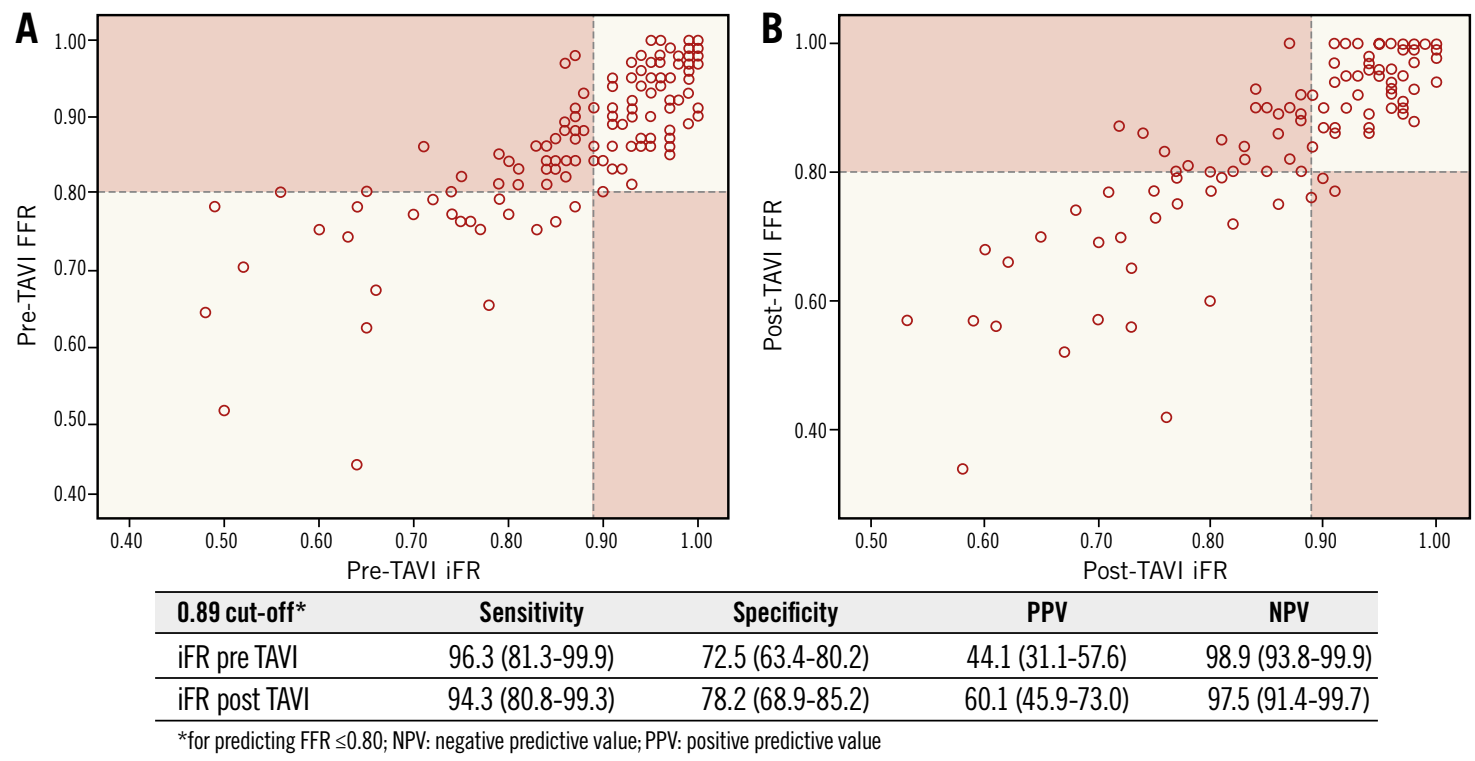

Figure 3. iFR-FFR classification agreement. A) Before TAVI. B) After TAVI. Dashed lines indicate the 0.80 FFR and 0.89 iFR cut-offs. The red blocks indicate the iFR-FFR disagreement zones.

Higher iFR variation before and after TAVI was associated with higher baseline mean aortic gradient $(\mathrm{r}=0.274, \mathrm{p}=0.009)$ and with a higher transaortic gradient drop after valve replacement ( $\mathrm{r}=0.494, \mathrm{p}<0.0001)$.

Conversely, the delta iFR pre and post TAVI was not significantly influenced by other baseline patient characteristics such as age $(r=0.57, p=0.52), L V$ ejection fraction $(r=0.078, p=0.439)$, interventricular septum wall thickness $(r=0.184, p=0.207)$, diabetes $(r=0.045, p=0.619)$, hypertension $(r=0.029, p=0.799)$, and baseline renal function $(\mathrm{r}=0.06, \mathrm{p}=0.529)$. Similarly, coronary lesion angiographic features such as \%DS ( $\mathrm{r}=0.035, \mathrm{p}=0.69)$, lesion length $(\mathrm{r}=0.01, \mathrm{p}=0.91)$ and reference vessel diameter $(\mathrm{r}=0.026, \mathrm{p}=0.78)$ did not influence the $\mathrm{iFR}$ variation pre and post TAVI.

Similarly, the iFR values pre and post TAVI were not influenced by procedural variables such as heart rate $(r=0.056, p=0.31)$ and blood pressure variations $(r=0.09, \mathrm{p}=0.23)$ after TAVI.

Likewise, no significant difference in functional measurements was detected between patients treated with balloon-expandable valves and those treated with self-expanding valves (Table 3).

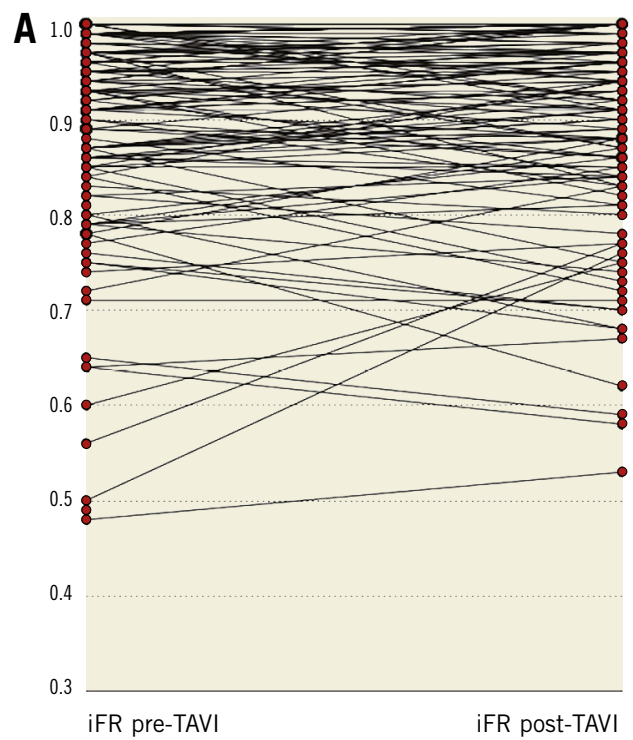

\section{B}

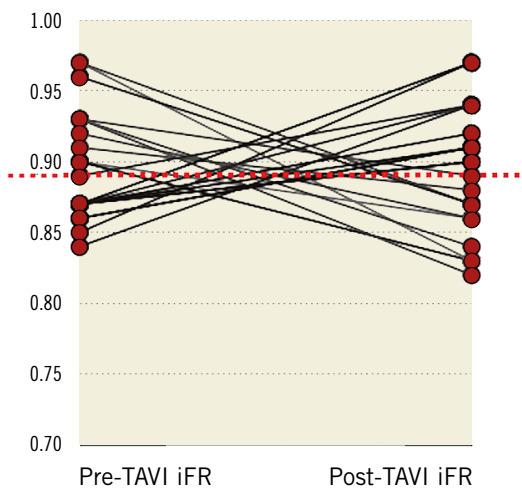

Figure 4. Individual iFR variations before and after TAVI. A) Overall individual iFR values in patients with AS before and after TAVI. B) Subgroup of coronary lesions that crossed through the $0.89 \mathrm{iFR}$ threshold after TAVI. Red dashed line indicates the $0.89 \mathrm{iFR}$ threshold. 


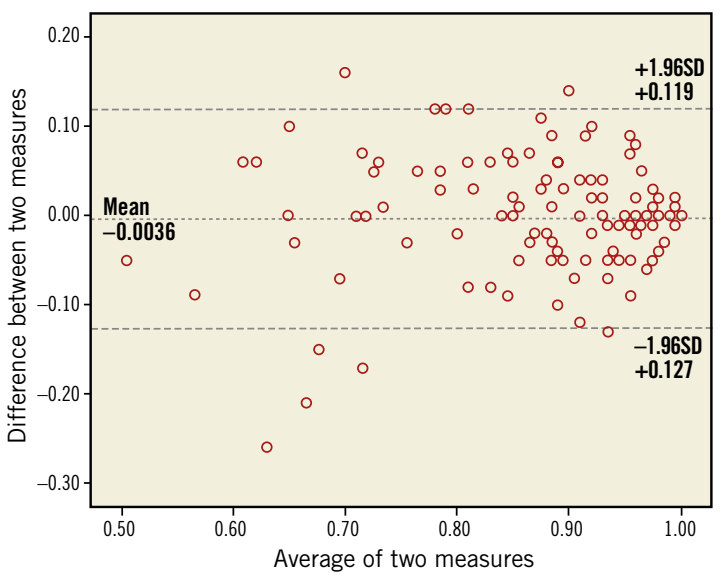

Figure 5. Bland-Altman plot of iFR pre-and post-TAVI measurements.

Table 3. Physiology assessment according to valve prosthesis type.

\begin{tabular}{|l|c|c|c|}
\hline \multicolumn{1}{|c|}{ Variable } & $\begin{array}{c}\text { Balloon- } \\
\text { expandable } \\
\text { valve }\end{array}$ & $\begin{array}{c}\text { Self- } \\
\text { expanding } \\
\text { valve }\end{array}$ & p-value \\
\hline Mean iFR ratio pre TAVI & $0.86 \pm 0.12$ & $0.81 \pm 0.14$ & 0.16 \\
\hline Mean FFR ratio pre TAVI & $0.86 \pm 0.09$ & $0.82 \pm 0.09$ & 0.11 \\
\hline Mean iFR ratio post TAVI & $0.85 \pm 0.11$ & $0.83 \pm 0.11$ & 0.32 \\
\hline Mean FFR ratio post TAVI & $0.84 \pm 0.13$ & $0.83 \pm 0.13$ & 0.71 \\
\hline Mean delta iFR ratio & $0.06 \pm 0.058$ & $0.056 \pm 0.043$ & 0.89 \\
\hline Mean delta FFR ratio & $0.05 \pm 0.047$ & $0.04 \pm 0.04$ & 0.41 \\
\hline $\begin{array}{l}\text { Coronary lesions with iFR } \\
\text { discordance pre post-TAVI, } \mathrm{n}(\%)\end{array}$ & $14(31 \%)$ & $7(33 \%)$ & 0.87 \\
\hline
\end{tabular}

\section{Discussion}

This study reports the very first observation of real-time iFR measurements in patients with severe AS undergoing TAVI. The main findings of the study are the following:

1) Overall iFR values remained stable before and after TAVI, along a broad range of coronary stenosis severity. However, individual iFR measurements showed a wide and erratic variation after TAVI in up to $15 \%$ of coronary lesions that crossed the 0.89 threshold after TAVI, potentially changing the indication for treatment between a pre- and a post-TAVI assessment in $27 \%$ of patients.

2) iFR yielded good diagnostic accuracy in predicting positive FFR. Indeed, the 0.89 cut-off demonstrated a high negative predictive value (NPV), so that significant lesions (defined as FFR $\leq 0.8$ ) would not be missed.

3) The iFR-FFR classification agreement is generally poorer in coronary obstructions with more severe angiographic and functional characteristics.

4) Delta iFR appeared to be influenced by the transaortic gradient drop induced by valve replacement but not by other patient or lesion characteristics.

Functional assessment with FFR in TAVI patients is feasible and safe $\mathrm{e}^{6,9,16}$. However, no validation of the FFR ischaemic cutoff in AS is available ${ }^{17}$, and some concerns are perceived among interventionalists regarding the use of vasodilators in this setting ${ }^{18}$.
Several factors might limit the achievement of maximal hyperaemia in patients with AS and therefore influence the FFR measurements. It has been proposed that some of the effects of AS on coronary physiology are immediately reversible after relieving the valve pressure gradient ${ }^{19}$, potentially increasing the reliability of the post-TAVI FFR measurements ${ }^{1}$.

iFR has demonstrated a high diagnostic agreement with FFR in stable CAD patients ${ }^{20-22}$, and recent large randomised trials demonstrated the non-inferiority of iFR-guided revascularisation compared to FFR-guided revascularisation ${ }^{23,24}$. In the specific setting of AS, iFR might facilitate a wider adoption of functional assessment of coronary lesions by obviating the need for high doses of vasodilators.

Although the average iFR measurements were identical before and after aortic valve replacement, a case-by-case analysis disclosed some erratic individual variations of iFR values between the preand post-TAVI measurements (Figure 4). Indeed, using the current $0.89 \mathrm{iFR}$ cut-off, the indications to treat a certain stenosis would be changed in $14.5 \%$ of lesions, and in $27.3 \%$ of patients after TAVI.

Recent data from the DEFINE-FLAIR and SWEDEHEART trials showed that the number of functionally significant coronary stenoses was lower in the iFR group than in the FFR group ${ }^{23,24}$. Interestingly, we observed an opposite trend in patients with severe $\mathrm{AS}^{25}$. The resting conditions in AS are in fact very different compared with CAD patients without aortic valve disease. The presence of baseline microvascular dilatation in AS has the function to compensate for the decreased perfusion pressure related to the valve obstruction ${ }^{9}$. At the same time, the microvascular resistances increased in severe AS because of endothelial dysfunction and extracellular compression forces ${ }^{3}$. The combination of these conditions leads to an increased resting flow, CFR exhaustion and to consequently lower iFR values.

The lower iFR values observed in AS compared with the average FFR values might reflect the lower CFR in $\mathrm{AS}^{8}$. On the other hand, the impaired hyperaemic response elicited by adenosine in AS may limit the achievement of maximal hyperaemic flow, resulting in a lower hyperaemic gradient and therefore in a higher FFR value. These concomitant conditions may be responsible for the different behaviour of iFR and FFR in AS compared with stable CAD patients.

These observations are supported by the recent evidence of a lower difference on average between the two indices calculated by Bland-Altman analysis and of a lower iFR cut-off for matching an FFR $\leq 0.8$ in AS compared with CAD (0.83 vs. 0.89$)^{25}$.

Interestingly, a lower rate of FFR variations across the cutoff was observed compared with iFR (8.3\% vs. $14.5 \%$ coronary lesions) in this study. This phenomenon could possibly be explained by the fact that the hyperaemic response elicited by adenosine is not instantly and completely restored by TAVI. As a consequence, FFR could be less likely to be able to detect significant variations of pressure gradient across a given stenosis compared with iFR immediately post TAVI.

Patients with more severe aortic valve gradients and higher gradient drop after TAVI showed a wider variation of iFR values. 
The change in the pressure load that occurs after TAVI reflects the increase in LV driving forces and the consequent increase in coronary flow. The close correlation of iFR with coronary flow measurements might explain the significant variations of iFR observed after TAVI.

Neither patient characteristics nor angiographic features were associated with delta iFR values. As a consequence, individual iFR changes after TAVI resulted in being unpredictable in some coronary lesions within a wide spectrum of angiographic stenosis and functional severity. Nevertheless, the 0.89 threshold yielded an elevated NPV (98\%) both at pre- and post-TAVI investigation. This fact is reassuring concerning the possibility of deferring intervention in intermediate coronary lesions without missing ischaemic ones with acceptable accuracy. On the other hand, the poor positive predictive value (PPV) limits the capability of iFR to detect ischaemia-provoking stenosis in AS before TAVI.

\section{Limitations}

The main limitation of the present study is that direct measurement of coronary flow was not performed. Assuming that iFR correlates highly with CFR, one may hypothesise that the changes observed in the iFR values depend on the coronary flow variations after TAVI. Therefore, the measurement of coronary flow could explain this point better. Further research is needed to understand iFR behaviour in the presence of severe AS.

Furthermore, no validation of FFR in AS is currently available and the conventional ischaemic cut-off for CAD assessment may vary in this setting.

Lastly, the sample size is limited. Nevertheless, this remains the largest report available on the real-time iFR-FFR assessment of coronary lesions before and immediately after aortic valve replacement.

\section{Conclusions}

Overall iFR values remained identical before and after AS removal. However, individual iFR measurements presented some unpredictable variations after the aortic valve replacement. This observation, along with the evidence of a correlation between delta iFR and the extent of the transaortic gradient drop after TAVI, confirms the variability of functional indices before and after the aortic valve replacement, and underlines the need for further studies dedicated to understanding iFR and FFR changes in severe AS.

\section{Impact on daily practice}

The peculiar setting of coronary microvascular circulation and the reduced coronary flow reserve in patients with severe aortic stenosis (AS) influence the iFR assessment of a bystander coronary stenosis. Our study demonstrated that iFR values crossed the 0.89 threshold in $15 \%$ of coronary lesions for $27 \%$ of patients after TAVI, potentially changing the indication for treatment. The interpretation of iFR measurement in patients with severe AS requires caution since it might be altered by the distinctive coronary conditions caused by the valve obstruction, and it might change significantly after aortic valve replacement.

\section{Funding}

This study was partially supported by a scholarship grant from Volcano Corporation.

\section{Conflict of interest statement}

The authors have no conflicts of interest to declare.

\section{References}

1. Danson E, Hansen P, Sen S, Davies J, Meredith I, Bhindi R. Assessment, treatment, and prognostic implications of CAD in patients undergoing TAVI. Nat Rev Cardiol. 2016;13:276-85.

2. Davies JE, Sen S, Broyd C, Hadjiloizou N, Baksi J, Francis DP, Foale RA, Parker KH, Hughes AD, Chukwuemeka A, Casula R, Malik IS, Mikhail GW, Mayet J. Arterial pulse wave dynamics after percutaneous aortic valve replacement: fall in coronary diastolic suction with increasing heart rate as a basis for angina symptoms in aortic stenosis. Circulation. 2011;124:1565-72.

3. Rajappan K, Rimoldi OE, Dutka DP, Ariff B, Pennell DJ, Sheridan DJ, Camici PG. Mechanisms of coronary microcirculatory dysfunction in patients with aortic stenosis and angiographically normal coronary arteries. Circulation. 2002;105:470-6.

4. Rajappan K, Rimoldi OE, Camici PG, Bellenger NG, Pennell DJ, Sheridan DJ. Functional changes in coronary microcirculation after valve replacement in patients with aortic stenosis. Circulation. 2003;107:3170-5.

5. Broyd CJ, Sen S, Mikhail GW, Francis DP, Mayet J, Davies JE. Myocardial ischemia in aortic stenosis: insights from arterial pulse-wave dynamics after percutaneous aortic valve replacement. Trends Cardiovasc Med. 2013;23:185-91.

6. Pesarini G, Scarsini R, Zivelonghi C, Piccoli A, Gambaro A, Gottin L, Rossi A, Ferrero V, Vassanelli C, Ribichini F. Functional Assessment of Coronary Artery Disease in Patients Undergoing Transcatheter Aortic Valve Implantation: Influence of Pressure Overload on the Evaluation of Lesions Severity. Circ Cardiovasc Interv. 2016;9: 004088.

7. Sen S, Escaned J, Malik IS, Mikhail GW, Foale RA, Mila R, Tarkin J, Petraco R, Broyd C, Jabbour R, Sethi A, Baker CS, Bellamy M, Al-Bustami M, Hackett D, Khan M, Lefroy D, Parker KH, Hughes AD, Francis DP, Di Mario C, Mayet J, Davies JE. Development and validation of a new adenosine-independent index of stenosis severity from coronary wave-intensity analysis: results of the ADVISE (ADenosine Vasodilator Independent Stenosis Evaluation) study. J Am Coll Cardiol. 2012;59:1392-402.

8. Petraco R, van de Hoef TP, Nijjer S, Sen S, van Lavieren MA, Foale RA, Meuwissen M, Broyd C, Echavarria-Pinto M, Foin N, Malik IS, Mikhail GW, Hughes AD, Francis DP, Mayet J, Di Mario C, Escaned J, Piek JJ, Davies JE. Baseline instantaneous wave-free ratio as a pressure-only estimation of underlying coronary flow reserve: results of the JUSTIFY-CFR Study (Joined Coronary Pressure and Flow Analysis to Determine Diagnostic Characteristics of Basal and Hyperemic Indices of Functional Lesion Severity-Coronary Flow Reserve). Circ Cardiovasc Interv. 2014;7:492-502. 
9. Wiegerinck EM, van de Hoef TP, Rolandi MC, Yong Z, van Kesteren F, Koch KT, Vis MM, de Mol BA, Piek JJ, Baan J Jr. Impact of Aortic Valve Stenosis on Coronary Hemodynamics and the Instantaneous Effect of Transcatheter Aortic Valve Implantation. Circ Cardiovasc Interv. 2015;8:e02443.

10. Joint Task Force on the Management of Valvular Heart Disease of the European Society of Cardiology (ESC); European Association for Cardio-Thoracic Surgery (EACTS), Vahanian A, Alfieri O, Andreotti F, Antunes MJ, Barón-Esquivias G, Baumgartner H, Borger MA, Carrel TP, De Bonis M, Evangelista A, Falk V, Iung B, Lancellotti P, Pierard L, Price S, Schäfers HJ, Schuler G, Stepinska J, Swedberg K, Takkenberg J, Von Oppell UO, Windecker S, Zamorano JL, Zembala M. Guidelines on the management of valvular heart disease. Eur Heart J. 2012;33:2451-96.

11. Zivelonghi C, Pesarini G, Scarsini R, Lunardi M, Piccoli A, Ferrero V, Gottin L, Vassanelli C, Ribichini F. Coronary Catheterization and Percutaneous Interventions After Transcatheter Aortic Valve Implantation. Am J Cardiol. 2017;120:625-31.

12. Ribichini F, Tomai F, De Luca G, Boccuzzi G, Presbitero P, Pesarini G, Ferrero V, Ghini AS, Abukaresh R, Aurigemma C, De Luca L, Zavalloni D, Soregaroli D, Marino P, Garbo R, Zanolla L, Vassanelli C; CEREA-DES investigators. Immunosuppressive therapy with oral prednisone to prevent restenosis after PCI. A multicenter randomized trial. Am J Med. 2011;124:434-43.

13. De Bruyne B, Gould KL. Standardized hyperemic stress for fractional flow reserve. Circ Cardiovasc Interv. 2013;6:602-3.

14. Tonino PA, De Bruyne B, Pijls NH, Siebert U, Ikeno F, van't Veer M, Klauss V, Manoharan G, Engstrøm T, Oldroyd KG, Ver Lee PN, MacCarthy PA, Fearon WF; FAME Study Investigators. Fractional flow reserve versus angiography for guiding percutaneous coronary intervention. N Engl J Med. 2009;360:213-24.

15. Park JJ, Petraco R, Nam CW, Doh JH, Davies J, Escaned J, Koo BK. Clinical validation of the resting pressure parameters in the assessment of functionally significant coronary stenosis; results of an independent, blinded comparison with fractional flow reserve. Int J Cardiol. 2013;168:4070-5.

16. Di Gioia G, Scarsini R, Strisciuglio $T$, De Biase C, Zivelonghi C, Franco D, De Bruyne B, Ribichini F, Barbato E. Correlation between Angiographic and Physiologic Evaluation of Coronary Artery Narrowings in Patients With Aortic Valve Stenosis. Am J Cardiol. 2017;120:106-10.

17. De Bruyne B, Baudhuin T, Melin JA, Pijls NH, Sys SU, Bol A, Paulus WJ, Heyndrickx GR, Wijns W. Coronary flow reserve calculated from pressure measurements in humans. Validation with positron emission tomography. Circulation. 1994;89:1013-22.

18. Sen S, Davies JE. Demystifying Complex Coronary Hemodynamics in Patients Undergoing Transcatheter Aortic Valve Replacement: Sowing the Seeds for Coronary Physiological Assessment in the Future? Circ Cardiovasc Interv. 2015;8:e002909.

19. Rolandi MC, Wiegerinck EM, Casadonte L, Yong ZY, Koch KT, Vis M, Piek JJ, Baan J, Spaan JA, Siebes M. Transcatheter Replacement of Stenotic Aortic Valve Normalizes
Cardiac-Coronary Interaction by Restoration of Systolic Coronary Flow Dynamics as Assessed by Wave Intensity Analysis. Circ Cardiovasc Interv. 2016;9:e002356.

20. Petraco R, Escaned J, Sen S, Nijjer S, Asrress KN, EchavarriaPinto M, Lockie T, Khawaja MZ, Cuevas C, Foin N, Broyd C, Foale RA, Hadjiloizou N, Malik IS, Mikhail GW, Sethi A, Kaprielian R, Baker CS, Lefroy D, Bellamy M, Al-Bustami M, Khan MA, Hughes AD, Francis DP, Mayet J, Di Mario C, Redwood S, Davies JE. Classification performance of instantaneous wave-free ratio (iFR) and fractional flow reserve in a clinical population of intermediate coronary stenoses: results of the ADVISE registry. EuroIntervention. 2013;9:91-101.

21. Jeremias A, Maehara A, Généreux P, Asrress KN, Berry C, De Bruyne B, Davies JE, Escaned J, Fearon WF, Gould KL, Johnson NP, Kirtane AJ, Koo BK, Marques KM, Nijjer S, Oldroyd KG, Petraco R, Piek JJ, Pijls NH, Redwood S, Siebes M, Spaan JA, van 't Veer M, Mintz GS, Stone GW. Multicenter core laboratory comparison of the instantaneous wave-free ratio and resting $\mathrm{Pd} / \mathrm{Pa}$ with fractional flow reserve: the RESOLVE study. $J$ Am Coll Cardiol. 2014;63:1253-61.

22. Petraco R, Park JJ, Sen S, Nijjer SS, Malik IS, EchavarríaPinto M, Asrress KN, Nam CW, Macías E, Foale RA, Sethi A, Mikhail GW, Kaprielian R, Baker CS, Lefroy D, Bellamy M, Al-Bustami M, Khan MA, Gonzalo N, Hughes AD, Francis DP, Mayet J, Di Mario C, Redwood S, Escaned J, Koo BK, Davies JE. Hybrid iFR-FFR decision-making strategy: implications for enhancing universal adoption of physiology-guided coronary revascularisation. EuroIntervention. 2013;8:1157-65.

23. Davies JE, Sen S, Dehbi HM, Al-Lamee R, Petraco R, Nijjer SS, Bhindi R, Lehman SJ, Walters D, Sapontis J, Janssens L, Vrints CJ, Khashaba A, Laine M, Van Belle E, Krackhardt F, Bojara W, Going O, Härle T, Indolfi C, Niccoli G, Ribichini F, Tanaka N, Yokoi H, Takashima H, Kikuta Y, Erglis A, Vinhas H, Canas Silva P, Baptista SB, Alghamdi A, Hellig F, Koo BK, Nam CW, Shin ES, Doh JH, Brugaletta S, Alegria-Barrero E, Meuwissen M, Piek JJ, van Royen N, Sezer M, Di Mario C, Gerber RT, Malik IS, Sharp AS, Talwar S, Tang K, Samady H, Altman J, Seto AH, Singh J, Jeremias A, Matsuo H, Kharbanda RK, Patel MR, Serruys P, Escaned J. Use of the Instantaneous Wave-free Ratio or Fractional Flow Reserve in PCI. $N$ Engl J Med. 2017; 376:1824-34.

24. Götberg M, Christiansen EH, Gudmundsdottir IJ, Sandhall L, Danielewicz M, Jakobsen L, Olsson SE, Öhagen P, Olsson H, Omerovic E, Calais F, Lindroos P, Maeng M, Tödt T, Venetsanos D, James SK, Kåregren A, Nilsson M, Carlsson J, Hauer D, Jensen J, Karlsson AC, Panayi G, Erlinge D, Fröbert O; iFR-SWEDEHEART Investigators. Instantaneous Wave-free Ratio versus Fractional Flow Reserve to Guide PCI. N Engl J Med. 2017;376:1813-23.

25. Scarsini R, Pesarini G, Zivelonghi C, Piccoli A, Ferrero V, Lunardi M, Barbierato M, Caprioglio F, Vassanelli C, Ribichini F. Coronary physiology in patients with severe aortic stenosis: Comparison between fractional flow reserve and instantaneous wave-free ratio. Int J Cardiol. 2017;243:40-6. 